\title{
Content, Object, and Phenomenal Character
}

\author{
Marco Aurélio Sousa Alves \\ The University of Texas at Austin
}

\begin{abstract}
The view that perceptual experience has representational content, or the content view, has recently been criticized by the defenders of the so-called object view. Part of the dispute, I claim here, is based on a lack of grasp of the notion of content. There is, however, a core of substantial disagreement. Once the substantial core is revealed, I aim to: (1) reject the arguments raised against the content view by Campbell (2002), Travis (2004), and Brewer (2006); (2) criticize Brewer's (2006, 2007, 2008, 2011) attempts to defend the object view; (3) refine Pautz' (2007, 2008, 2009, 2010, 2011) arguments against the object view, which mainly resort to the fact that it cannot account for the grounding role of hallucinatory experiences; (4) and finally adjudicate in favor of the content view and against the overestimation of the naïve intuition.
\end{abstract}

Keywords: Content view; object view; representational content; phenomenal character; naïve intuition.

\section{Introduction}

The view that perceptual experience has content became a current orthodoxy. Recently, however, the very idea of experiences having contents was challenged and this is now a debating point in philosophy of perception. Part of the dispute, or so I claim here, is based on misunderstanding concerning the notion of content. There is, however, a core of substantial disagreement. My aim here is, first, to reveal where the real issue lies, and, then, to evaluate the main alternatives.

The paper is organized in the following way. (I) First, the two views in conflict are introduced: the content view and the object view. ${ }^{1}$ (II) Then, some arguments against the content view advanced by Campbell (2002), Travis (2004), and Brewer (2006), are considered and rejected; (III) The object view is then refined, following Brewer's version of it, and some arguments in its favor (involving mainly his account of illusion) are criticized; (IV) I finally consider the hallucinatory case and a crucial argument against the object view: the grounding intuition; ${ }^{2}$ (V) The last section summarizes the debate and adjudicates in favor of the content view.

\section{The notion of content}

The views in dispute here are theories concerning the nature of perceptual experience. As I use the term perceptual experience, it necessarily has a phenomenal charPrincipia 16(3): 417-449 (2012).

Published by NEL — Epistemology and Logic Research Group, Federal University of Santa Catarina (UFSC), Brazil. 
acter, or what it is like to undergo that experience. If I taste a passion fruit, smell roses, run my fingers over a velvet coat, hear a violin, or see a ripe tomato, in each of these cases I am the subject of different experiences. For perceptual experiences, there is always something it is like to undergo them. In what follows, I will be mainly concerned with the following question: what accounts for the phenomenology of our perceptual experiences? ${ }^{3}$

Perceptual experiences are typically classified by philosophers in three types: veridical perception, illusion, and hallucination. In a veridical perception, the perceived object is as it appears to be. If I see a red and bulgy tomato before me, for instance, and there is in fact a red and bulgy tomato there, I have a veridical perception. In cases of illusion, the perceived object is not as it appears to be. If, for example, a yellow and crescent-shaped banana before me looks rather like a red and bulgy tomato, I am having an illusion. In a hallucination, contrary to the other kinds of perceptual experience, there is no perceived object. Though there is no genuine contact with particular objects in the world on the hallucinatory occasion, hallucinations involve a conscious portrayal of the world as being some way: I have the visual experience of a red and bulgy tomato before me, for example, though there is nothing there. Our experiences of (veridically) seeing, ${ }^{4}$ having an illusion, or hallucinating, all have a certain phenomenal character (the way they look like). All these types of experience (veridically seeing a red and bulgy tomato, or illusory seeing a banana as a red and bulgy tomato, or hallucinating a red and bulgy tomato) can share, I assume here, the same phenomenal character. The very same phenomenology of visually experiencing a red and bulgy tomato can be present in all these cases, but in the first case the tomato is really there, in the second a yellow banana is actually perceived, and in the third case there is no object at all being perceived. I am concerned here with the best account of the phenomenal character of our sensory experiences, which can possibly be shared among veridical perceptions, illusions, and hallucinations. ${ }^{5}$

The content view characterizes the phenomenal character of a perceptual experience in terms of the contents (properties, objects, and relations) that are represented by that experience. The subjective quality (or the what-it-is-like) of a perceptual experience is (at least partly) equated with what is represented by that experience. ${ }^{6}$ When I see a red and bulgy tomato before me, for example, the phenomenal character of that experience can be (at least partly) explained by the fact that my experience represents some color and shape properties (redness and bulginess), as well as a certain object (the tomato) and a relation (being in front of me) ${ }^{7}$ Details apart, the core idea of the content view is that the phenomenology of a sensory experience is (at least in part) explained by what is represented by that experience. Understood as an intentional relation, representing is not committed to the representata being actually instantiated before the perceiver. In the case of a veridical perception of a red

Principia 16(3): 417-449 (2012). 
and bulgy tomato, the object and properties being represented are actually there. In this case, the representational content is not merely intentional, but it is also actual. However, in nonveridical cases (i.e., illusions and hallucinations), the represented properties and/or objects are nonactual, or merely intentional. If I illusorily perceive a yellow banana as being red, for example, the property redness is represented by my experience, though it is not instantiated before me. And when I hallucinate a red tomato, both the property redness and the object (the tomato) are represented by my experience, even though they are nonactual. According to the content view, both veridical and nonveridical cases can share the same content: they can all represent the same properties, objects and relations. ${ }^{8}$ The possibility of having a shared content accounts for the possibility of having a shared phenomenal character, since the content view consists exactly in explaining the phenomenal character in terms of the representational content. ${ }^{9}$

The object view, on the other hand, characterizes the phenomenal character of a perceptual experience in terms of obtaining a direct relation between subject and external objects and their properties. As Martin (2004, p.64) famously put it, when one sees, the external objects and their properties "shape the contours of the subject's conscious experience". This metaphor of "shaping the contours" must be interpreted here in a constitutive sense, as opposed to a merely causal one. If, for example, the contours of a certain landscape are altered by the event of an earthquake, the earthquake itself does not constitute the landscape, though it may have caused some drastic changes (the mountains are now lower, for instance, and the lake changed its location). The relevant sense here, however, is that in which the hills are said to shape the contours of a landscape. The hills constitute the contours, or they are the contours. This is the sense in which the object view claims that external objects and their properties shape the contours of our perceptual experiences. Campbell (2002, p.116) also has this constitutive sense in mind when he claims that "the phenomenal character of your experience, as you look around the room, is constituted by the actual layout of the room itself".

First of all, it must be noted that the object view is primarily concerned with veridical perceptions. When I veridically see a red tomato, for instance, I am directly related to the tomato and its redness, and the obtaining of that relation accounts for the phenomenal character of my experience. So far nothing was said about nonveridical experiences. In the following sections, we will see how the object view can be extended to account for the phenomenology of illusory and hallucinatory experiences.

Secondly, it must be highlighted that the object view appeals to a direct relation. ${ }^{10}$ The obtaining of a direct relation between subject and things perceived is what accounts for the phenomenal character of an experience. The relation is direct, in the relevant sense here, if it cannot be obtained in the absence of the perceived things.

Principia 16(3): 417-449 (2012). 
The object view gives a fundamentally relational account of phenomenal character: our sensory phenomenology is accounted for in terms of a relation whose relata are a subject $S$, on the one side, and external objects and their properties, on the other side. The second relatum is not an intentional object, or a representatum, but worldly objects and properties themselves. The direct relation must be understood as a primitive relation, which cannot be reduced to any more basic relation. As a consequence, being directly related to certain objects and properties cannot be equated with perceptually representing certain objects and properties. The direct relation, in opposition to the representational relation, can only obtain if actual objects and properties are instantiated before the perceiver.

Consequently, the crucial difference between the content and the object views concerns how they understand the way in which external objects and properties determine the phenomenal character of perceptual experiences. According to the content view, the subjective qualities are "properties the experience represents things as having" (Dretske 2003, p.67), and "the world needn't contain them [properties and things one is aware of] in order to be represented as containing them" (Dretske 2003, p.71). The content view characterizes the phenomenal character as the property of a given experience of representing some properties and objects. The representational relation holds even if the represented properties and objects do not exist or are not instantiated in the perceived scene. According to the object view, on the other hand, it follows from the content view that "the contours of the subject's conscious experience will not be shaped by the actual layout of the world, but rather by the layout the world is represented to have" (Fish 2009, p.14). The gap between represented things and the things themselves is taken very seriously by the object view.

Michael Tye (1992, p.160) once said that on a bright sunny day on the beach in Santa Barbara he found himself "transfixed by the intense blue of the Pacific Ocean". The content view, espoused by Michael himself, says that the peculiar phenomenology of that experience consists in representing the color property "intense blue" as instantiated. Even if Michael had seen no Ocean at all (he was, say, actually at home doing some experiments with mescaline), or if the Pacific Ocean were actually light green and Michael had the illusion of it being intense blue, all those experiences could share the same content and, therefore, the same phenomenal character. By contrast, the object view claims that the intense blue experienced by Michael could not be the very instance of the Pacific Ocean's color if it could still be experienced in illusory or hallucinatory cases.

As it may be clear by now, the content and object views do not exhaust the theoretical space. The object view is not simply the negation of the content view. There is plenty of space for alternatives that reject both views. However, the object view seems to imply the rejection of the content view: the role played by the representational content in determining the phenomenal character of perceptual experiences

Principia 16(3): 417-449 (2012). 
is central to the content view, and it is explicitly denied by the object view. This denial is sometimes put in the following way: the object view denies that perceptual experiences have representational contents.

The claim that perceptual experiences have contents seems to be central to the dispute. My first effort here is to offer an interpretation of this claim that makes it worth discussing. As an upshot of this effort, we will reach a better grasp of what the content view amounts to. As noticed by Pautz (2009), some current conceptions of content trivialize the debate whether or not experiences have contents. What makes these conceptions trivial is the fact that they do not concern directly the phenomenal character of perceptual experiences. In other words, these conceptions do not state explicitly that the phenomenal character is at least part of what is being explained by the notion of content. Pautz (2009, p.483) detects two such trivial approaches: the appears-looks conception and the accuracy conception. The only conception, he claims, that makes the debate substantial, is the identity conception. I expound now these conceptions and why a more theory-laden notion of content is necessary to avoid trivializing the debate. ${ }^{11}$

According to the appears-looks conception, the content of an experience is given by the analysis of appears-looks reports. Byrne and Hilbert (2003, p.5), for example, affirmed that "the proposition that $p$ is part of the content of a subject's visual experience if and only if it visually appears to the subject that $p$ ". According to this conception, a given experience has the proposition $\mathrm{p}$ as its content if, in having that experience, it appears-looks to the subject that $p$. For example: if it appears-looks to me that a tomato is red, then my experience has the content $<$ a tomato is red $>$. It is stipulated that an experience is veridical if and only if its appears-looks contents are true: if my appears-looks report that a tomato is red is true, then my corresponding experience is veridical.

As it stands, the appears-looks conception trivializes the debate over whether experiences have contents. Given the stipulative equation between appears-looks reports and the contents of perceptual experiences, the claim that perceptual experiences have contents is equated with the trivial claim that experiential episodes are associated with appears-looks reports. Pautz (2009, p.487) claims that the appearslooks conception turns debates about representational contents uninteresting because "they will amount to debates about the truth-values of appears-looks reports in ordinary English". Of course, such debates are worth pursuing in their own right. The claim here is that the very fact that perceptual experiences have contents becomes trivial in this conception. ${ }^{12}$

The accuracy conception, on the other hand, defines content in terms of accuracy conditions. Siegel (2006, p. 361), for instance, claims that "the content of an experience is given by the conditions under which it is accurate". Like beliefs or maps, perceptual experiences have contents, and just as the contents of beliefs are con-

Principia 16(3): 417-449 (2012). 
ditions under which a belief state is true, and the contents of maps are conditions under which a map is an accurate depiction of a spatial area, so the contents of perceptual experiences are conditions under which the experience is accurate. The accuracy conception claims, therefore, that experiences are the kind of things that can be accurate or inaccurate, and that their contents are conditions under which they are so. If something is accurate, then there is something else in relation to which it is accurate. In the case of a perceptual experience, it is inaccurate if there is a mismatch between experience and perceived scene. In the absence of any mismatch, the experience is accurate.

Given the stipulations above, there is a shortcut argument for the claim that experiences have contents: experiences are accurate or inaccurate (intuitive premise); therefore they have accuracy conditions; and (by definition) these conditions determine their contents. ${ }^{13}$ The obvious questions are how we are going to determine the accuracy conditions (and therefore the content), and how they are supposed to account for the phenomenal character of experience.

In the accuracy conception, accuracy is simply defined as successful depiction of bits of the world. But this notion of content is also trivial for our purposes: it simply follows from the unqualified (or ordinary) idea that experiences can be accurate or inaccurate. Different theorists can give radically different accounts of something "being accurate". The mere platitude that experiences can go wrong is a datum with no theoretical weight. It is, of course, open to any theorist to give his or her favored account of this piece of common sense. Travis (2004), for instance, accounts for misperception in terms of higher-order states, such as beliefs and judgments, that mistake the perceptually given for something else. Even in a view along these lines, we can be misled by experiences. From this platitude, it does not follow any substantive thesis concerning the very existence of representational contents.

The crucial problem of the appears-looks and the accuracy conceptions is that they don't specify how experiences are associated with contents. If the theorist is free to offer any account whatsoever of this connection, the claim that experiences have contents becomes theoretically uninteresting. If experiences trivially have contents, what is being denied by those who reject this claim? It is also unclear what explanatory role the notion of content is supposed to be playing. Something more substantial must be at stake.

The relevant disagreement between content-friends and content-enemies, as noted by Pautz (2009, p.491), concerns the thesis that "the 'subjective character' of perceptual experience is to be given by its representational content". This way of putting things highlights the explanatory role played by the notion of content: it explains, or gives the real definition, of phenomenal character. In order to have this explanatory power, and to be nontrivial, Pautz (2009, p.492) claims that the connection between content and experience must be of identity: having an experience

Principia 16(3): 417-449 (2012). 
is identical with standing in a certain relation to its content. This is what he labels the identity conception. Given that conception, my first-pass definition of the content view becomes more precise now: the phenomenal character of a perceptual experience is (at least in part) equated with its representational content. ${ }^{14}$ And that is precisely what is denied by the object view.

\section{Missing the target: Campbell, Travis, and Brewer}

I consider in this section some arguments against the content view that, for various reasons, are not sound. Given the nontrivial interpretation of the claim that experiences have contents, discussed in the last section, I argue that the arguments considered below simply misfire. They aim at denying the thesis that experiences have contents, but they miss the relevant target.

First I examine the main argument presented by Campbell (2002). ${ }^{15}$ He claims that the content view cannot give a satisfactory account of what makes it possible for us to have thoughts about singular external objects. ${ }^{16}$ If you are to know what my use of a demonstrative expression such as "that tomato" refers to, when I say that "that tomato is bulgy", you must be able to perceptually single out the relevant object that I am talking about. Perceptual singling out seems required for us to have knowledge of the reference of demonstratives. Assuming that we can have knowledge of this kind, it follows that an adequate account of perceptual experience must explain what grounds this kind of knowledge.

In Campbell's (2002, p.45) terms, the conscious perceptual attention to an object "must be thought of as more primitive than thought about an object", since the first ability grounds the second one. According to Campbell, the content view treats perceptual experience as just one way among many of being intentionally related to contents. If I think about a certain tomato or if I have a visual experience of that tomato, for instance, both states have the same content, and there is nothing about the perceptual relation, understood in intentional terms, that distinguishes the perceptual relation from the intentional relation of thinking about the tomato. However, if experience is to explain our capacity to think about particular objects, the kind of relation between subject and perceived object must be more primitive or more direct than the intentional relation between thoughts and their objects. Because of that, Campbell believes that only the object view, in defending a kind of direct relation with perceived objects, can satisfactorily account for the grounding role of perception.

The kind of direct perceptual relation defended by Campbell can only take place if the object perceived exists and is properly related to the subject. In discussing the difference between veridically perceiving a dagger and hallucinating a dagger,

Principia 16(3): 417-449 (2012). 
Campbell (2002, p.117) says that "in the case in which there is a dagger, the object itself is a constituent of your experience. The experience is quite different in the case of hallucination, since there is no object to be a constituent of your experience". However, as noted by McLaughlin (2010, p.244), the mere idea of perceived objects being constituents of experience does not capture the essential difference between the content view and the object view. As it stands, it is still open for to the content view to maintain that in veridical perception the objects are constituents of the experience. Nothing blocks the content view from maintaining that, in a veridical perception, the subject bears a direct relation to the perceived object. The relation of veridically seeing an object, for instance, can be defined as essentially containing the object as the relatum of that relation. McLaughlin (2010, p.244) stresses that Campbell's remarks leave open "whether the visual perceiving of the object is identical with the visual experience with the representational content or is instead distinct from it". Since the content view can go either way on that issue, Campbell does not offer a compelling reason against the content view.

Campbell's case against the content view relies on the premise that the content view is "committed to saying that it is in virtue of its representational content that experience can play its explanatory role" (Campbell, 2002, p.147), and the key explanatory role that he has in mind is that of "explaining our ability to think demonstratively about perceived objects" (p.114). However, as emphatically stated by McLaughlin (2010, p.250), this premise is "simply wrong". The explanatory burden addressed by Campbell is transversal to the dispute between the content and the object views. The content view can perfectly maintain that the fact that an experience is an experience of a certain object explains certain matters, and the fact that the experience has a certain representational content explains certain other matters. McLaughlin (2010, p.251) accuses Campbell of mistakenly assuming that the content view is committed to the idea that "whatever an experience explains in virtue of being an experience of an object (or of a certain object), the experience explains in virtue of its representational content". The content view, as we saw in the last section, is a thesis about the phenomenal character of perceptual experiences. It says that phenomenal character is (at least partly) equated with representational content. Nothing that Campbell says seems to directly affect this thesis. Being an experience of a certain object and being an experience with a certain representational content can play different explanatory roles.

The fact that the grounding role is not explained in terms of representational content does not mean that the content view has no other means of satisfying this explanatory demand. What makes my experience of that tomato, for instance, the experience that it is goes much beyond the fact that that tomato is part of its representational content. Other intentional attitudes, like thinking about the tomato, can share the same content. These two states (perceiving the tomato and thinking 
about the tomato) cannot be distinguished by their representational contents: both have the same content, namely the same tomato. The two states also do not differ in whether or not they are intentional, since both states are defined as intentional by the content view. Nonetheless, they may differ in various other ways. The perceptual and the thinking relations may, for instance, incorporate different kinds of intentionality, which may differ, among other things, in their higher-order functional roles. The object of perception can be the input of a thought, but the pure object of a thought cannot become the sensible object of a perceptual experience. This asymmetry may be used to differentiate functionally different kinds of intentional states, one being, in a certain sense, more "primitive" than the other. Even if that explanation is not satisfactory, it cannot be simply assumed, as Campbell does, that any intentional relation must be of a single kind, in every respect. Moreover, as qualified in the last section, the content view claims that perceptual experiences are relations to contents. The relation between subject and perceived object is, in part, representational, and that part accounts for the phenomenal character of experiences. But nothing in the content view requires that the only admissible relation between subject and perceived object is representational. Besides representing certain things, experiences can also, for example, be caused by worldly objects, and this causal connection can be used to ground the capacity to refer demonstratively to worldly objects. This is, as a matter of fact, the standard explanation of demonstrative thought associated with the content view. ${ }^{17}$ The causal account is, in a certain sense, analogous to the causal theory of proper names: my capacity of thinking about Aristotle may be grounded in the causal chain that links my thoughts to Aristotle himself. On the same token, my capacity of thinking about a particular tomato may be grounded in the tomato causing my perceptual experience of it.

It is surprising that Campbell does not argue against any alternative explanation open to the content view. He (2002, p.116) wants to deny the view according to which "the phenomenal character of your experience is constituted not by the way your surroundings are, but by the contents of your representational states", but his arguments do not touch the content view itself, understood as a theory about phenomenal character. Moreover, I share with McLaughlin (2010) the opinion that Campbell does not motivate his version of the object view against the classical challenge raised against it: if phenomenal character is accounted for by a direct relation with worldly objects and their properties, as he seems to defend, then what explains the phenomenal character of illusions and hallucinations? He is silent on that matter, and he is not entitled to be so.

I consider now the arguments raised by Travis (2004) against the content view. Travis (2004, p.57) characterizes his target as the view that "a (given) perceptual experience has a (given) representational content". He is particularly concerned with the claim that perceptual experiences are the kind of things that can be true or false.

Principia 16(3): 417-449 (2012). 
Truth and falsity, he insists, arise only in beliefs or judgments; perception itself is not capable of error. He credits this view to Austin (1962), from whom he quotes the following passage: "though the phrase 'deceived by our senses' is a common metaphor, it is a metaphor [...]. In fact, of course, our senses are dumb [...], our senses do not tell us anything, true or false" (Austin 1962, p.11).

For the sake of exposition, I divide his main argument in two parts. According to Travis, the attractiveness of Austin's view comes in part from the impossibility of determining the representational content of a given experience. This is the first part of his argument. But this impossibility, he claims, should not be seen as a problem. After all, "for what I perceive to be misleading, nothing needs to be represented as so" (Travis 2004, p.64). Travis insists that the notion of representational content is not necessary to explain misperception. This is the second part of his argument.

First part: Travis assumes that the content view is committed to explaining how the content of a given perceptual experience is determined. He also assumes that this specification procedure consists in analyzing ordinary looks-reports. According to Travis, by analyzing the use of the term "looks" (and other terms that we may use to speak of how things look), we may try to determine the content of particular experiences. This procedure, in order to work, depends on the hypothesis that content is "looks-indexed" (Travis 2004, p.63). If content is "looks-indexed", then it can possibly be extracted from the way things are said to look (through some kind of linguistic analysis of looks-reports). After investigating our looks-reports, however, Travis (2004) concludes that they cannot index content. The existing reports either fail to isolate a strictly phenomenal element, as when one says that "that tomato looks expensive", or they are a matter of "factive meaning" (or things indicating to the perceiver that the perceived scene is so-and-so), as in the case of a ring on a tree trunk representing a year's growth. Travis (2004) then claims that in the only kind of looks-report that seems to be relevant, representing collapses into indicating. According to Travis (2004, p.78), "what things look like on this use of 'looks' is thus a matter of what things mean factively, or indicate", and this, he insists, is "precisely not a matter of things being represented as so". ${ }^{18}$

Travis' assumptions, that (i) the content view must provide a procedure for determining specific contents of given experiences, that (ii) this procedure must involve the analysis of looks-reports, and that (iii) this analysis depends on contents being looks-indexed, are all of them controversial. In fact, I don't feel inclined to accept any of them. Given the rejection of the appears-looks conception of content (discussed in the last section), the failure of a looks-index account of content should not be worrisome at all. That is why Pautz (2009, p.497) and Byrne (2009, p.444) simply grant that Travis (2004) is right here: content is not looks-indexed. This claim, however, has hardly any effect on the substantial thesis that experiences have contents. ${ }^{19}$

In order to be as charitable as possible, I propose the following interpretation of

Principia 16(3): 417-449 (2012). 
Travis' first point. The linguistic-analysis surface of his argument actually points to a deeper issue concerning the very nature of representation. Travis (2004, p.62) sees perception as a source of information of the surroundings. In this sense, representations can be committed or uncommitted. Perception, he claims, is a kind of uncommitted representation, in a sense akin to the sense in which sentences in English are not committed to things "being some way rather than another" (Travis 2004, p.61). Take for instance the sentence "Pigs swim". An assertion of this sentence is committed to things being thus and so, but the sentence itself (or the embedded proposition) cannot be said to be true or false, since it is not committed to the world being any particular way. Indeed, the English sentence "Pigs swim" may be used for stating that pigs swim, but in itself the mere embedded proposition is not committed to things being any particular way. The distinction between committed and uncommitted representations motivates Travis' (2004, p.62) claim that perceptual experiences have no face value: "with uncommitted representation, there is nothing either to accept or reject; nothing purportedly so".

According to Travis (2004), perceptual experience is a kind of "natural representation", and natural representation is simply not the kind of representation implied in the notion of representational content. The "occurrence" or "instancing" of an uncommitted representation does not mean anything by itself. It may indicate many things, but the job of taking it as representing anything at all must be done by the representer. Travis (2004, p.62) compares perception with the following case of natural representation: the bald patches on a cat can be taken as indicating that it has mange. The patches themselves don't mean anything. Analogously, perceptual experiences do not mean anything themselves. They are symptoms of the world, and they can be taken by a representer as indications of various different things: that the cat has mange, or that it has burns all over the body, or that it played with a razor, etc.

In the more charitable interpretation proposed here, the analysis of looks-reports are simply used to suggest that the very notion of representational content (or the idea that perceptual experiences are representational states) is misguided. When properly understood, the notion of representational content collapses into the idea that experiences simply indicate how the world is. ${ }^{20}$

Second part: Travis (2004, p.64) defends Austin's idea that "rather than representing anything as so, our senses merely bring our surroundings into view; afford us some sort of awareness of them". In that respect, "senses are dumb": they are not the kind of things that can be in error. Error is a matter of misjudging, or "failing to make out what I confront for what it is" (Travis 2004, p.65). If I see bald patches on a cat and misjudge that it has mange (when, in fact, the cat was born that way), my senses do not misrepresent anything. It is me who failed to make out what I see for what it is. That is an error of judgment, not an error of perception. The main point here is that misperception can be accounted for without any appeal to representa- 
tional content. It is the very scene perceived that is misleading. The misjudgment that things are thus-and-so cannot be simply equated with taking a perceptual content at its face value. Misperceiving, according to Travis (2004), consists in taking certain misleading information as erroneously indicating something that is not the case. Perception is informative only in the sense of bearing factive meaning (like the patches on a cat, or the rings in a tree trunk). But factive meaning does not allow error. If the cat with bald patches does not have mange, the patches do not misrepresent anything. The patches are simply misleading. The difference between "factively meaning" and "indicating" is spelled out by Travis (2004, p.66-7) in the following way: "if A factively means B, then (if) A, B"; while "A, in indicating B, may be misleading just in virtue of what it might have been expected to mean".

Travis' strategy, in a nutshell, is the following: there is no non-arbitrary way of determining the content of a given experience. No problem, he says: it has no content. The purportedly explanatory job of representational content (explaining misperception, or perceptual error) cannot be done by this notion anyway. But this job can be done, he claims, by the notion of indicating. Perceptual error, contrary to the content view, is a matter of misjudging misleading perceptual information (information that is not itself true or false; that has no face value). The upshot is that representational content is not a consistent notion, but we don't need it anyway.

Travis' argument, nonetheless, even in its more charitable interpretation, fails to make a relevant point against the content view. He may bring some insights concerning an alternative account (a certain version of the object view), but his denial of the content view misses the target. ${ }^{21}$ Even if we ignore the assumption that the method for determining contents must be the analysis of appears-looks reports (which, we granted, does not work), the mere requirement of having any such method seems misplaced. I fail to see why the content view should be obliged to offer a general procedure for determining specific contents for given perceptual experiences (or some kind of detailed explanation of everything that is represented in particular perceptual experiences).$^{22}$ In what concerns the claim that there is a problem with the very notion of representational content, I believe that it equally fails to touch upon the content view itself. Why is the content view in trouble if representational contents are understood as uncommitted representations? Why would this be any relevant to the account of phenomenal character? The motto "perception itself is not capable of error" is orthogonal to the very notion of content. Travis (2004) just assumes that contents must explain perceptual error, but that is wrong. Content explains (or constitutes) the phenomenal character. Content is not (directly) in the business of explaining perceptual success, at least not necessarily. The idea that perceptual experiences, in some sense, cannot be true or false, is perfectly compatible with the content view. ${ }^{23}$ Most part of the disagreement here, it seems to me, is merely verbal. It depends on one's favored use of terms like "being veridical", or "being in error". 
In a certain sense, perception is not true or false; in another sense, it is trivially the case that one can go wrong in perception. If in one's favored terminology "being in error" is used only for judgments, fair enough. If the predicate "being false" cannot be attributed to experiences, that is fine too. ${ }^{24}$ And finally, even if some substantive point lies behind these verbal disputes, the content view is neutral on any substantive account of perceptual success.

I finally consider some of the points that Bill Brewer (2006, 2007, 2008, 2011) raised against the content view. He substantially improved upon ideas that were very sketchy in Campbell (2002) and Travis (2004). He developed recently a fairly detailed version of the object view and offered a substantial account of illusion. In this section, I consider one of his arguments against the content view: the generality problem. An overall assessment of his positive proposals will be done in the next section.

Brewer (2006, p.166) claims that the content view is based upon the spurious extension of two features of the contents of thoughts to the contents of perceptions. The first one (i) is that contents can be true or false; the second (ii) is that contents involve a certain generality. Brewer believes that both features are problematic when applied to perceptual experiences. Concerning the first feature, Brewer develops an alternative framework in which the idea of content cannot be made to have any interesting use. That will be discussed in the next sections. In this section, I focus on one of his arguments against the second feature.

According to Brewer (2006, p.173), perceptual content is general because the properties it represents stand for indefinitely qualitatively distinct things, that fall within the range determined by the general property. Take, for example, Michael's experience of intense blue (or blue ${ }_{27}$, say). His experience represents a certain shade of blue, but this property is general, since it stands for qualitatively distinct hues: blue $_{27,2}$, blue 27,33 , etc. According to Brewer, the represented property in Michael's example stand for hues within a certain range (between blue 26,5 and blue 27,5 , say), consequently it is a general property, and not the particular intense-blue which is actually instantiated by the Pacific Ocean.

Brewer (2006, p.174) argues against the generality of content in two ways. First, he appeals to the "fundamental intuition" that in perception constituents of the physical world are presented to the subject. ${ }^{25}$ This point involves an important intuition, the naïve intuition, which will be further discussed in the next sections. For the time being, I focus on his second point: the circularity argument. Brewer (2006, p.175) claims that the content view is circular: "perceptual experience is to be characterized by its representational content, which is in turn to be identified by a certain procedure which takes as its starting point a worldly situation in which that very content is supposed to be determined as true". He (2006, p.175) assumes that the "procedure" for determining the range covered by a certain general content is some 
"kind of generalization from a paradigm instance of its actual truth". The problem, then, is that in order to know if the paradigm case is true, we must know which general property is being represented, whereas in order to know the property, we need the truth-conditions of the paradigm case. Given this circularity, there is no way of determining the accuracy-conditions that define perceptual content.

The circularity argument is clearly based on the assumption that perceptual content is determined by its accuracy conditions. The accuracy conception of content, however, was already rejected in the last section. Content is not in the business of explaining (alone) which experiences are accurate. Content (sorry for repeating this mantra) explains, among possibly other things, the phenomenal character of perceptual experience. Whatever (general properties or what not) constitutes the contents of experiences, it does not have to account (directly) for the accuracy of particular experiences. Moreover, as remarked before, the content view is not committed to provide a "procedure" for determining the contents of perceptual experiences. Consequently, the circularity argument misses the point and does not touch upon the content view itself.

\section{Naïve intuition and illusions}

The content view gives an elegant and straightforward explanation of the phenomenology of nonveridical experiences. The content (and thus the phenomenal character) can be the same among veridical and nonveridical experiences. The subjective indistinguishability between those experiences, in the content view, is explained in terms of a shared content. Since perceptual experience is seen as a relation to content, and contents are, in a sense, representata, the phenomenology of experience is explained even in the absence of any mind-independent physical object being actually perceived. This possibility of having the relation to content in the absence of the perceived object gives to the content view a very easy time dealing with the classical arguments from illusion and hallucination. Absent objects or uninstantiated properties pose, in principle, no problem to the content view. The common factor element that explains the phenomenal character possibly shared among veridical and nonveridical experiences is simply the content. Since no actual objects (physical objects, sense data, or any entity of some funny ontological kind) are needed to explain the phenomenal character of perceptual experiences, the content view avoids (at least in part) some well-known ontological difficulties. Given all these virtues, it is no surprise that the content view has been widely regarded, since the downfall of the sense-data theory, as the best account of perceptual experience. Contrary to orthodoxy, Brewer argues, first, that there is an alternative view, second, that this alternative is better, and, finally, that the content view has problems in its own right to explain illusions.

Principia 16(3): 417-449 (2012). 
The object view, as characterized in the first section, says that the phenomenal character of a perceptual experience is characterized by a direct relation with mindindependent physical objects. But why should someone defend this view instead of the content view? We have just listed some of the various virtues of the content view. A quick look at the object view shows that it will have a hard time dealing with nonveridical experiences. In order to understand the seductiveness of the object view, we have to adopt a different starting point.

First, we must acknowledge a crucial intuition: "perceptual experience presents us directly with the objects in the world around us themselves" (Brewer 2006, p.167). This intuition, in its interesting sense, concerns also the phenomenology of perceptual experiences. Since, in perceptual experiences, we are directly presented with worldly objects, why aren't the objects phenomenally manifest to us, in a direct way? Why isn't the phenomenal character explained, directly, by the encounter with objects in the world? According to Brewer (2006), the underlying reason why the content view cannot do full justice to this intuition is its original motivation: the phenomenal content is, in important respects, similar to the content of thoughts. Given that similarity, Brewer (2011, p.56) argues that the notion of content cannot "account for the fundamental difference between perception and thought: perception is an experiential presentation of the physical world around us", whereas thought is not. This is, in a nutshell, the naïve intuition. ${ }^{26}$

I want to emphasize the phenomenological reading of the naive intuition: it concerns the very nature of phenomenal character. Pautz (2010, p.295) remarks that slogans to the effect that objects must be "directly present in experience", or must "constitute essentially experience", are imprecise and may lead to confusion. The only sense in which the naïve intuition is relevant to the content view is as concerning the phenomenology of perceptual experiences.

The naïve intuition is taken by Brewer as a datum: any theory of phenomenal character is committed to accommodate this intuition. Starting from this acknowledgment, Brewer builds up his positive account of phenomenal character. Brewer's account of illusion follows an important insight from Travis (2004): the phenomenology of nonveridical experiences is to be explained by the fact that perceived objects "have the power to mislead us" (Brewer 2006, p.168). The phenomenology of illusions, which is an obvious challenge for the object view, is explained in terms of the subject's response to the world. An explanation of illusion along these lines can save the intuition that mind-independent physical objects are presented to us in experience, though, maybe, in misleading ways.

Brewer's (2006, p.172) account of the phenomenal character of perceptual experience has two levels: first, there is "the mind-independent direct object itself", as constitutive of the phenomenal character; and, second, there is "the way in which the object is perceptually taken". The "way the object is taken" includes a given point 
of view, a particular sense modality, and certain circumstances of perception (such as lighting conditions, for example). All the elements that determine the perceptual condition amount together to a third relatum of perceptual experience: a subject $S$ experiences object $o$ in way $W$. I quote now two excerpts in which Brewer states his account:

A mind-independent physical object, $o$, looks $F$ to a subject, $S$, in virtue of the fact that $S$ is consciously visually acquainted with $o$ from a point of view and in circumstances of perception relative to which $o$ has visually relevant similarities with paradigm exemplars of $F$, where visually relevant similarities are similarities of the various kinds to which the physical processes enabling visual perception respond similarly, as a result of both their evolutionary design and their development over the course of our lives. (Brewer 2011, p.118).

From various points of view, and in various circumstances of perception, physical objects have visually relevant similarities with paradigms of various kinds of such things. These may intelligibly lead us to take them as instances of such kinds [...]. Illusions are cases in which the direct object of experience has such similarities with paradigms of a kind which it is not in fact an instance. (Brewer 2007, p.91).

Some of the ideas contained in these passages need to be unpacked. Consider Brewer's (2011, p.120) own illustration. Subject $S$ sees a duck. Relative to a given viewpoint and circumstance of perception, the duck has visually relevant similarities with paradigm ducks, and thus it looks "ducklike". The "relevant similarities" are de facto similarities between physical objects, and the relation of "being visually similar with some paradigm exemplars of a kind $F$ " should not be confused with the application of a certain concept. The kind $F$, that determines a range of paradigm exemplars, is not, strictly speaking, a concept. A kind $F$ is some sort of gestalt property ("being ducklike", for instance), and it is used to ground the application of properly associated concepts by concept-users (the concept $<$ duck $>$, for instance). In this sense, something "being similar to a paradigm exemplar of a certain kind" does not involve the application of concepts (at least not directly). Given that qualification, perceptual experiences of sentient creatures that are not concept-users (such as infants and animals) pose no particular problem to the theory.

If, for instance, subject $S$ is in Twin-Earth and sees a twin-duck, or if, in the actual world, $S$ sees duck ${ }_{2}$ (a perfect replica of the first duck), Brewer's theory is committed to saying that $S$ has different experiences in each case (since the objects are different, and the perceived objects constitute the phenomenal character). Assumed that viewpoint and perceptual circumstance are kept constant, Brewer claims that the subjective indistinguishability of these experiences is accounted for in terms of

Principia 16(3): 417-449 (2012). 
the objects having the same visually relevant properties (and thus, by consequence, the same relevant similarities with paradigm exemplars of the same kind $F$ ). In all these cases (duck, twin-duck, duck ${ }_{2}$ ), whatever object is perceived, it looks ducklike. Looking ducklike accounts, thus, for the subjective indistinguishability of all these different experiences. The "relevant similarities" are determined by the objective capacity of mind-independent objects to affect our sensory systems in certain ways. A fully developed explanation of what relevantly affects our perceptual system may include evolutionary design, cognitive capacities, or whatever is found to be empirically relevant to account for our encounter with objects in the world. What makes some similarities relevant is, according to Brewer (2011, p.102), a "largely empirical" question. A question that involves some properties of physical objects (such as light reflectance), the operations of our sensory system, some evolutionarily developed abilities, some cognitive skills, and so on.

As I said before, Brewer does not restrict himself to formulating a positive alternative view: he also claims that the content view fails to account satisfactorily for illusions. Consider the classical case of the Müller-Lyer illusion. Brewer claims that the content view describes the case roughly in the following way: a subject entertains a perceptual experience that consists in being related with a certain representational content. The content (that gives the phenomenology of the experience) represents two lines of unequal length. Brewer (2006, p.169) then asks: "how exactly would the world have to be for the purported perceptual representation to be veridical?" The question here should not be confused with the requirement of a general procedure for determining representational contents. The point pressed here is that the content view faces a dilemma: either the content is not determinate (which conflicts with the thesis that perceptual content is maximally determinate) or the content is impossible. Since none of the horns is any promising, Brewer concludes that the content view faces a serious challenge. ${ }^{27}$

Consider the second horn of the dilemma. According to Brewer (2006), in the Müller-Lyer experience, the endpoints of the lines are seen in their exact right place, though the lines are represented as having unequal lengths. This is an impossible combination, of course. Given the impossible (contradictory) combination of represented elements, there is no way the world could be to make this content true. But if an illusion has an impossible content, then one could know by reflection that it is nonveridical. This would eliminate the illusory character of the experience. The impossible content could not be representing the world, since there is no way of changing the world and making the content veridical.

However, the account suggested by Brewer is not the only one available to the defender of the content view. One possibility, offered by Pautz (2009, p.498), is to deny that the representational content is false, and claim that the lines look unequal only because the perceiver is "disposed to believe falsely that they are different in length". 
This reply, however, is "quite implausible", according to Brewer (2011, p.65): "the illusory look remains even for perceivers with no such inclination because they are fully aware of the illusory nature of the diagram". But Brewer's reply does not settle the matter. Pautz could appeal to a mere disposition to believe, which does not amount to actually believing anything. In this case, knowledge of the illusory nature of the diagram would function as a defeater of the inclination to believe that the lines are in fact unequal in length, but the inclination itself could still remain.

Maybe the most important point here is not how good the alternative formulated by Pautz is, but how Brewer's argument is not compelling. It leaves the content view with many options. Consider, for instance, the following alternative. The representational content may be regarded as relative to what is consciously attended to. Attending to the endpoints of the lines is one experience, with a certain representational content; attending to both lines at once is another experience, with another content. None of the experiences in isolation have an impossible content. Brewer (2011, p.69) acknowledges this alternative, but insists that "since the whole combination is not possible, the content view is indeed committed to impossible overall representational contents". But now I fail to see the problem. Impossible combinations of different experiences are ordinary phenomena. When we have seemingly contradictory experiences, we just take a second look and check if we have got something wrong. In the Müller-Lyer case, if the perceiver, in fact, consciously attends to the endpoints of the lines, then attends to both lines at once, and finally compares both experiences, she will be puzzled (assuming that memory is working fine, and so on). Maybe she will think that there is an illusion going on, that one of her experiences (or both of them) misrepresents the diagram. What I fail to see is why the Müller-Lyer diagram must keep its illusory powers of inclining the perceiver to a false belief, no matter how she looks at it, or how hard she works on comparing its various looks. From a certain perspective, in certain conditions, and being attended in certain ways, the illusion is robust. And that is all that needs to be accounted for.

Brewer (2011) also formulates another argument. The content view, he argues, lacks the adequate resources to account for the boundaries distinguishing illusions from hallucinations. I call this the illusion-limits argument. After a certain point, it is unlikely that an experience is illusory, instead of hallucinatory. Depending on the degree of mismatching, an experience can lose the right to be illusory. In an illusion, an object $o$ illusorily looks $F$, while in a hallucination no object is presented, so nothing looks any way. In the first case, according to Brewer, the object itself has an "objective look", or de facto similarities with paradigms, and, under certain conditions, it can be illusorily perceived. Still, asks Brewer (2011, p.73), can the Müller-Lyer lines look like a perfect circle, or can a rabbit some feet away look like the Eiffel Tower? According to Brewer, (2011, p.73), "perceptual presentation is in general incompatible with extreme error". If a particular object $o$ is, in fact, being

Principia 16(3): 417-449 (2012). 
presented, it is not the case that any error whatsoever can occur. After a certain point, the very presentation of that object is implausible: it becomes implausible that the phenomenal character is really due to the object presenting itself in the experience. Contrary to hallucinations (which are not cases of objects being presented), illusions have limits. And the content view, unlike the object view, cannot explain these limits.

Brewer (2011, p.74) considers the following reply. The limits, may say his opponent, are "merely contingent upon the nature of the environment and the workings of subjects' perceptual systems". Though Brewer agrees that the limits are, in great part, a contingent empirical matter, there is a sense in which, given a fixed situation (viewpoint and circumstance of perception), some phenomenal experiences are just not compatible with the genuine presentation of certain particular objects. In fairly ordinary perceptual conditions, a rabbit cannot look like the Eiffel Tower. This cannot be a case of the subject being perceptually acquainted with a rabbit. The very idea of "objects being presented in experience", or "subjects being perceptually acquainted with objects", cannot be reasonably applicable to such cases. The main idea here, says Brewer (2011, p.74), is that "there are limits beyond which an object fails to be genuinely presented in perception regardless of its causal involvement in the production of a representation with the relevant false content". That there are such limits, insists Brewer, is a datum, and the content view lacks the adequate resources to account for that.

Though thought-provoking, the illusion-limits argument is another case of misunderstanding of the explanatory role of content. Content does not have to account for what makes an experience an experience of a certain object. As far as content goes, there are no limits to how extreme an illusion can be. However, the content view is free to adopt any account of what makes an experience an illusion. It can pick, for instance, the view that the various powers of objects to produce certain phenomenal experiences, given certain experiential conditions, explain the bounds of illusion. This is, of course, a massively empirical question, and the content view is perfectly compatible with any such empirical explanation. The only difference between the accounts of the illusion-limits of the content view and the object view, it seems to me, is that the former locates the constraints in contingent causal facts concerning the relation between perceiver and world, whereas the latter takes the contingent facts (relevant similarities, or perceptual conditions) to constitute the experience itself. Both theories give massively empirical explanations of the illusion-limits, and nothing bars any of the theories from adopting the best empirical explanation available in their frameworks. The defender of the content view is free to give any account of "being suitably connected to an object", and that account can perfectly explain the relevant datum. Pautz (2010, p.287) also remarks that, in order to be an experience of an object, causation is surely not enough: a "suitable degree of match between the object and the experiential content" is also necessary. The explanation given by

Principia 16(3): 417-449 (2012). 
the object view to this matching relation is at least as complicated and involves as much contingent empirical facts as the ones available for the content view.

\section{Hallucination, the grounding intuition, and negative disjunctivism}

Though Brewer does not have a compelling argument against the content view, as I argued in the last section, it may still be the case that his positive account fares better than its competitors. For the sake of argument, I grant that Brewer offers a satisfactory account of illusion within the object view framework. But what about hallucinations? I believe that hallucinations pose a much deeper challenge for the object view.

As I use this term here, the grounding intuition is the pretheoretical intuition that, in hallucinating, the subject can, in principle, acquire the capacity to have novel beliefs involving phenomenal properties (colors, shapes, etc.). I slightly modify Pautz' (2010) formulation and spell out the grounding intuition in the following way: intuitively, if an individual who has the capacity to have beliefs has a hallucinatory experience, this individual can (possibly) thereby acquire the additional capacity of having novel general beliefs. ${ }^{28}$

The force or compelling character of this intuition is well illustrated by Johnston (2004). ${ }^{29}$ In the course of investigating the nature of hallucinatory states, Johnston (2004) defends, among other things, the thesis that hallucinations can secure original reference to qualities, and, by so doing, hallucinations can ground de re knowledge of qualities. According to Johnston (2004, p.130), "Frank Jackson's Mary could come to know what red is like by hallucinating a red thing or by having a red afterimage". The idea here is that, intuitively, Mary can, by means of a hallucination, come to grasp new properties that can ground beliefs of the following kind: "this shade of red is different from that shade of blue". Phenomenal qualities, argues Johnston (2004), are directly presented to the hallucinator: this explains how hallucination can ground de re knowledge of qualities. If some kind of de re knowledge can find its ground on hallucination, there must be a res to which hallucination is a relation to. There must be, in this sense, an object of hallucination that constitutes its content.

Johnston (2004) also presents an interesting experiment that supports the grounding intuition. After being exposed to a bright monochromatic unique green light in a dark room for a certain time, the room is illuminated and the subject afterimages a small red patch, which is then superimposed on a small red background, causing the subject to have a supersaturated red afterimage. ${ }^{30}$ The supersaturated red is more saturated than any visible red in normal circumstances. This is a color that can never be (veridically) seen, but only afterimaged. This experiment sup-

Principia 16(3): 417-449 (2012). 
ports the thesis that novel qualities can be experienced by means of hallucinatory experiences. ${ }^{31}$

The pressing question is how the object view can possibly account for the grounding intuition. Or, in other words, how can the object view account for the nature of hallucinatory experiences? In what follows, I do not argue against any possible account of hallucination available, in principle, for the defender of the object view. My immediate target will be a specific kind of approach: the negative disjunctivist account of hallucination.

Disjunctivism is characterized in many different ways in the literature. ${ }^{32}$ As I use this term here, it comprises, among possibly other things, a claim concerning the phenomenology of perceptual experience. What is accounted for disjunctively is the very nature or "real definition" of perceptual experience, and that includes the phenomenal character. The association of the object view with disjunctivism is a very natural one. ${ }^{33}$ The object view takes the naïve intuition as its starting motivation. According to the naïve intuition, the phenomenology of perceptual experiences is determined by worldly objects presenting themselves in experience. Given that there are no such objects being presented in hallucinations, we have an obvious problem. The way out of this problem is to explain the phenomenal character of hallucinatory experiences in some different way. ${ }^{34}$

The object view is then committed to adopt some sort of disjunctivist approach: the phenomenal character of perceptual experience is a matter of either a physical object being presented in experience or something else that accounts for hallucinations. But what could substitute the something else in the second disjunct? The answer to this question distinguishes positive from negative disjunctivist accounts. The negative version characterizes hallucinatory experiences in terms of some relation to veridical cases. The positive version, on the other hand, explains hallucinatory experiences in terms totally independent of veridical cases. ${ }^{35}$ In this paper, I confine myself to the negative account. ${ }^{36}$ This restriction of scope, of course, makes my argument here incomplete. But the elements that can be extracted from this restricted debate are, I believe, enough to suggest a strong charge against the object view. Moreover, most defenders of the object view, Bill Brewer included, adopt some version or other of negative disjunctivism. ${ }^{37}$

The following characterization of the negative disjunctivist account of hallucination, defended by Brewer, will serve as a working definition:

Hallucinatory experiences have to be characterized by giving a qualitative description of a more or less specific mind-independent scene, and saying that the subject is having an experience that is not distinguishable by introspection alone from one in which the constituents of such a scene are the direct objects. (Brewer 2010, p. 110).

The grounding intuition, it seems to me, is not compatible with the negative Principia 16(3): 417-449 (2012). 
disjunctivist account of hallucination. According to the grounding intuition, the subject is perceptually introduced to novel properties, or properties that can endow her with a newly acquired capacity to have beliefs involving this property. How can a merely negatively defined state (i.e., "having a hallucination is not having such-andsuch") explain the apparently substantial nature of hallucination? As well remarked by Dancy (1995, p.436), negative disjunctivism characterizes hallucination "solely by saying that it is like what it is not". But such characterization leaves the very nature of hallucinatory states totally obscure. The crucial question is what accounts for the phenomenal character of hallucinatory experiences. The novel properties introduced by hallucinations may not have been experienced before by the subject, as illustrated by Mary's hallucination of a red patch or by the afterimage of supersaturated red. As it stands, the negative account does not explain why hallucinations have the phenomenology they have, or how they can be like veridical perceptions.

My argument here goes as follows: (premise 1) having a hallucinatory experience can endow the subject with a new capacity; (premise 2) a merely negative condition cannot account for that novel capacity; (conclusion) a hallucinatory experience cannot be equated with a merely negative condition.

Premise 1 simply sates the grounding intuition. ${ }^{38}$ Premise 2 , however, is more controversial. According to my working definition of negative disjunctivism, that I took from Brewer (2011, p. 110), the relevant condition for being a hallucinatory state is characterized as "being indistinguishable by introspection alone" from veridical cases. This condition describes a relation that may hold or not: if it holds, on one side, we have a veridical experience, and, on the other, we have a hallucination. What matters here is that the very nature of the second relatum is defined negatively in terms of the first one. This is so because the relation is defined in purely negative terms. Pautz (2010, p.278) argues that the mere failure to satisfy the negative condition (i.e., "being indistinguishable by introspection") can hardly explain the positive attributes of hallucinations. As Pautz (2010, p.278) remarks, "irrelevant counterexamples aside, if $a$ 's possessing $F$ explains $a$ 's possessing $G$, then if $a$ had not possessed $F$, $a$ would not have possessed $G$ ". ${ }^{39}$ In the case at hand, $A$ having a hallucination explains $A$ having the capacity to have certain beliefs (given premise 1 ), then, ceteris paribus, had $A$ not had the hallucination, $A$ would not have the capacity to have these beliefs. But now, if we consider the negative condition ("being indistinguishable by introspection"), we see that it is not intuitively true that if $A$ had not been in an state that is indistinguishable by introspection from so-and-so, then $A$ would not have the capacity to have certain beliefs.

The conclusion of the argument (i.e., negative disjunctivist accounts of hallucination are not consistent with the grounding intuition) should not be surprising. Negative disjunctivists emphasize veridical perceptions and try to explain nonveridical cases in terms of the veridical ones. Consequently, nonveridical cases (such as

Principia 16(3): 417-449 (2012). 
hallucinations) cannot add any new (substantial) element that cannot be somehow extracted from the veridical ones. Surely, hallucinations cannot introduce new $o b$ jects to thoughts, since there are no objects being presented in hallucinations. But, as Pautz (2010, p.279) stresses, "there do not merely exist particular objects; there also exist such things as general properties". ${ }^{40}$ The object view is happy to use the grounding intuition when it comes to objects, but they adopt an "unjustified double standard" when it comes to properties. ${ }^{41}$

Brewer (2011) argued later against the use of the grounding intuition against the negative account of hallucinations. He (2011, p. 112) claimed that "negative conditions' are often perfectly explanatory, as, for example, when an accident is explained by a driver failing to spot a cyclist". Though negatively defined, he insists that "hallucinatory conditions are not blank". Brewer interprets the negative disjunctivist strategy as a mere theoretical characterization of a class of thick things: namely, the hallucinations. Having a hallucination, in this thick sense, is being in some condition or other. The negative characterization ("being in an state that is indistinguishable from so-and-so") is a mere theoretical delineation of a class of things that cannot be given a unified definition, since they don't fall under any substantive general class. The negative definition is the only one that can capture what, by its nature, is a class of diverse things. Concerning the role of grounding beliefs, Brewer (2011, p.112) asks: "If it is perfectly clear how, had the subject's condition been one of actually seeing an $F$ instead, this would have explained her capacity for beliefs whose content contains $F$, then why would a condition indistinguishable from this not have served equally well?"

The cyclist example given by Brewer is infelicitous. If we are after a material explanation of a certain event (say, an accident), the lack of attention of the driver cannot enter in the picture. In this kind of explanation, the relevant cause is, say, the car moving in a certain direction, or the arms of the driver doing this-and-that, and so on. The kind of explanation that is pressed by the grounding intuition involves the capacity to have certain de re beliefs. The lack of something cannot explain that. The rhetorical question that closes the last paragraph also misses the point. The grounding intuition asks for a constitutive explanation of how one can have certain beliefs. If the mere fact that hallucinating is subjectively indistinguishable from seeing is enough to explain the grounding problem, then hallucinations should also be allowed to ground de re beliefs about unicorns, dwarfs, and Santa Claus. The grounding problem does not concern what one may take to be the case, but the very nature (or constitution) of mental states. Without the appropriate res, de re attitudes are just not available.

Brewer also attacks premise 1, or the grounding intuition itself. He (2011, p.113) claims that having beliefs involves certain cognitive abilities and the use of concepts. Suppose that the subject $A$ believes that the object $o$ is red. This can only happen 
if the concept <red $>$ is at $A$ 's disposal. The term concept is used here in a broad sense: it may either be a thick concept (which implies that $A$ is a concept-user and can use the concept $<$ red $>$ in thoughts), or a thin concept (which involves some specific cognitive ability, such as tracking certain objects or properties, or grasping a gestalt property). Either way, Brewer argues that hallucinations fail to provide the required concept. In a hallucination, there is no tracking of any existing object or any instantiated property to ground concept-possession. As a consequence, there is no concept $<$ red $>$ (be it thick or thin) that can possibly be provided by hallucinations. Indeed, if properties like < being red > are to be understood as de re, or as being reducible to worldly stuff, then the possession of the thick concept $<$ red $>$ must be grounded by the grasp of some thin concept, and that is exactly what is being denied. Mere hallucinations, concludes Brewer, cannot provide the necessary material to ground beliefs: they are not cognitively robust enough for that.

Brewer's point can be further supported by the case of agnosia. The visually agnosic can identify some features of the object, but he fails to identify visual kinds. If an agnosic looks at a duck, he has a certain phenomenal experience, but he lacks the capacity to have beliefs involving gestalt properties such as <being ducklike $>$, or $<$ being roundish-like $>$. The use of agnosia to support Brewer's point seems straightforward: hallucinatory experience, like the agnosic's experience, has a certain phenomenological character, but it lacks the capacity to ground beliefs.

Pautz (2009, p.39) offers a convincing reply to the agnosic case. Whatever impoverished experience the agnosic has (say, the duck looks like "a lot of grayish dots"), it endows him with the capacity to have de re beliefs involving these impoverished experienced properties. The agnosic can have beliefs such as "these dots are darker than those ones". Though the agnosic does not acquire gestalt concepts, he comes to grasp new de re elements for reference. The upshot of this reply is that the grounding intuition still stands with the mere capacity to ground non-gestalt-based beliefs. Brewer, it seems to me, tends to equate cognitively loaded processes with ground-floor perceptual experiences. The strictly perceptual element is thinner than Brewer's coarse cognitive apparatus.

Consider now what Pautz (2008, p.46) calls the tracking requirement, which consists in the cognitive requirement that, in order to have a belief concerning a certain property (<being red >, say), the believer must have tracked actual instances of objects with that property. As we have seen above, Brewer (2011) appeals to such requirement in his argument against the grounding intuition. The requirement seems unproblematic to him because the property in the belief is equated with a gestaltlike property, and acquiring a gestalt-like property involves attentional tracking of objects that keep the relevant property (<being roundish-like $>$, say) unchanged across variations in viewing conditions. Only this kind of cognitive item, he believes, can ground demonstrative reference. Given the absence of any trackable particular 
in hallucinations, Brewer (2011, p.112) concludes that, contrary to the grounding intuition, hallucinatory experiences cannot offer items for demonstrative thoughts.

The tracking requirement, however, is not a legitimate requirement. On that matter, Pautz (2008, p.47) appeals to intuition: the grounding intuition is stronger than this heavily-theoretically-loaded requirement. But, as I see it, the intuitive response is unsatisfactory. Brewer is explicitly denying this intuition. Empirical evidence plus a bit of theorizing can, in principle, show that an intuition that is pretheoretically entrenched does not survive further evidence.

I thus propose another line of attack. Even if we grant, for the sake of argument, that tracking a gestalt-like property is essential to acquiring a new de re belief including that property, it is not clear that the mere tracking attitude cannot take place in hallucinations. The putative object of a hallucination (e.g., Macbeth's dagger) has all the attributes necessary for being the object of a tracking attitude. ${ }^{42}$ The dagger can, for instance, keep its properties unchanged across variations in viewing conditions and perceptual circumstances. If the relevant gestalt-like property is the property of < being dagger-like>, Macbeth's dagger can perfectly fit the bill. This is even a consequence of defining hallucinations as subjectively indistinguishable from veridical perceptions. The only difference is that, in seeing, we track a real dagger, and, in hallucinating, Macbeth tracks a hallucinatory dagger. ${ }^{43}$ My point here is that the tracking requirement collapses into the issue concerning what object is being tracked. The tracking attitude itself can be present in hallucinations. What is not there is the tracked object. But, remember, the whole point here concerns the possibility of hallucinations providing de re properties, not objects (of course). Even if the capacity of consciously perceiving properties in fact requires some kind of tracking attitude, hallucinations can perfectly provide that. ${ }^{44}$

The grounding intuition, I conclude, does present a convincing argument against the negative disjunctivist account of hallucination. The object view is, as a consequence, in real trouble. The negative account of hallucination gave to the defender of the object view the hope of an easy way out of the classical metaphysical difficulties faced by the positive accounts of hallucinations, but this hope, as I argued here, is illusory.

\section{Closing remarks}

The naïve intuition is the main motivation for the object view. In fact, given all the difficulties that the object view faces (principally concerning the account of hallucinatory experiences), the naïve intuition seems to be the only potential argument for this view.

Can the content view accommodate the naïve intuition? Pautz (2010, p.291) offers good reasons to doubt that. ${ }^{45}$ In its deepest sense, the naïve intuition implies 
an account of phenomenal character that is entirely at odds with the content view. The pressing question, then, is the following: Can we reject the naïve intuition?

As a matter of fact, there is a prima facie plausibility in the naïve intuition. It is a real intuition. It is, as Pautz (2010, p. 286) remarks, "built into our very concept of seeing". We intuitively think that the objects of our experiences really constitute the experience's phenomenology. Though very intuitive, no specific explanation is given to how, or in which sense, objects constitute one's phenomenology. Maybe the whole idea behind this intuition is some sort of Austin-Travis tendency of giving too much importance to the way we ordinarily speak of perception. The intuition may be simply built in the way we talk of "seeing". More importantly, the naïve intuition is in itself unclear. Pautz (2010, p.296) remarks that the whole idea that phenomenal character is the way it is "by-virtue-of" the presentation of the object is entirely obscure. The "by-virtue-of" relation is not spelled out. And even if one attempts to do so, the precise account will not come out naturally from the intuition: the precise definition of the "by-virtue-of" relation will be a theoretically-loaded claim that could hardly be said to follow from the original pretheoretical intuition itself. The reason why this is not explicitly accounted for, I think, is simply because it is, in fact, just a mere intuition. It is based, maybe, on the way we ordinarily talk about perception. As far as the intuition goes, the locution "by-virtue-of" can be spelled out in various ways. The theorist is completely free to do the job: the intuition itself does not settle the matter. The main idea here is that the intuition itself does not directly support any specific claim concerning the determination of the phenomenal character of perceptual experience. If we move beyond the pretheoretical layer, which springs from the way we talk and intuitively think about these matters, we realize that our pretheoretical understanding can hardly serve as a guide.

If the naïve intuition is all the defender of the object view has to offer, I conclude that he is in serious trouble. The object view is a huge effort to save the naïve intuition, but the payoff of this attempt has been shown to be meager. Campbell (2002) and Travis (2004) do not argue convincingly against the content view and do not offer any alternative (in particular, they are very vague or say nothing about illusions and hallucinations). More sophisticated versions of the object view, as the one advocated by Brewer, don't offer a convincing account of nonveridical experiences. There are, surely, other alternatives in the philosophical space. The current map of philosophy of mind is too complex and full of alternatives: conclusive arguments are more and more unlikely to happen. If anything, I want this paper to be a contribution to the huge inference to the best explanation that still supports, as far as I can see, the content view. ${ }^{46}$

Principia 16(3): 417-449 (2012). 


\section{References}

Austin, J. 1962. Sense and Sensibilia. Oxford: Oxford University Press.

Brewer, B. 2004. Realism and the Nature of Perceptual Experience. Philosophical Issues 14:

61-77.

- 2006. Perception and Content. European Journal of Philosophy 14: 165-81.

- 2007. Perception and its objects. Philosophical Studies 132: 87-97.

- 2008. How to Account for Illusion. In A. Haddock \& F. Macpherson (eds.) Disjunctivism: Perception, Action, Knowledge. Oxford: Oxford University Press.

- 2011. Perception and Its Objects. Oxford: Oxford University Press.

Byrne, A. 2001. Intentionalism Defended. Philosophical Review 110: 199-240.

- 2009. Experience and Content. The Philosophical Quarterly 59: 429-51.

Byrne, A. \& Hilbert, D. 2003. Color Realism and Color Science. Behavioral and Brain Sciences 26: 3-21.

Byrne, A. \& Logue, H. 2008. Either/Or. In A. Haddock \& F. Macpherson (eds.) Disjunctivism: Perception, Action, Knowledge. Oxford: Oxford University Press.

Campbell, J. 2002. Reference and Consciousness. Oxford: Oxford University Press.

. 2009. Consciousness and Reference. In B. McLaughlin \& A. Beckerman (eds.) Oxford Handbook of Philosophy of Mind. Oxford: Oxford University Press.

Dancy, J. 1995. Arguments from Illusion. Philosophical Quarterly 45: 421-38.

Dretske, F. 2003. Experience as Representation. In E. Villanueva (ed.) Philosophical Issues, Vol. 13: Philosophy of Mind. Atascadero, CA: Ridgeview, p.67-82.

Fish, W. 2009. Perception, Hallucination, and Illusion. Oxford: Oxford University Press.

Harman, G. 1990. The Intrinsic Quality of Experience. Philosophical Perspectives 4: 31-52.

Hawthorne, J. \& Kovakovich, K. 2006. Disjunctivism. Proceedings of the Aristotelian Society 80 Supp.: 145-83.

Hinton, J. 1973. Experience: An Inquiry into Some Ambiguities. Oxford: Clarendon Press.

Hurvich, L. 1982. Color Vision. Sunderland, MA: Sinauer Associates.

Jackson, F. 1977. Perception: a Representative Theory. Cambridge: Cambridge University Press. Johnston, M. 2004. The Obscure Object of Hallucination. Philosophical Studies 120: 113-83. . 2006. Better than Mere Knowledge? The Function of Sensory Awareness. In T. Szabo

Gendler; J. Hawthorne (eds.) Perceptual Experience. Oxford: Oxford University Press.

Kalderon, M.; Travis, C. 2009. Oxford Realism. In M. Beaney (ed.) Oxford Handbook of the History of Analytic Philosophy. Oxford: Oxford University Press.

Martin, M. 2002. The Transparency of Experience. Mind \& Language 17: 376-425.

- 2004. The Limits of Self-Awareness. Philosophical Studies 120: 37-89. . 2006. On Being Alienated. In T. Szabo Gendler \& J. Hawthorne (eds.) Perceptual Experience. Oxford: Oxford University Press.

McDowell, J. 1986. Singular Thought and the Extent of Inner Space. In J. McDowell; P. Pettit (eds.) Subject, Thought, and Context. Oxford: Clarendon Press.

McLaughlin, B. 2010. The Representational vs. the Relational View of Visual Experience. Royal Institute of Philosophy Supplement 67: 239-62.

Nielsen, E.; Lyon, M.; Ellison, G. 1983. Apparent hallucinations in monkeys during aroundthe-clock amphetamine for seven to fourteen days. The Journal of Nervous and Mental Disease 171: 222-33.

Principia 16(3): 417-449 (2012). 
Pautz, A. 2007. Intentionalism and Perceptual Presence. Philosophical Perspectives 21: 495541.

2008. How Visual Consciousness Reaches to the World. Unpublished. Available online at https://webspace.utexas.edu/arp424/www/index.html?uniq=tpfy1b

$(07 / 26 / 2012)$.

- 2009. What Are the Contents of Experiences? Philosophical Quarterly 59: 483-507. 2010. Why Explain Visual Experience in Terms of Content? In B. Nanay (ed.) Perceiving the World. Oxford: Oxford University Press.

- 2011. Can Disjunctivists Explain Our Access to the Sensible World? Philosophical Issues 21: 384-433.

Siegel, S. 2006. Subject and Object in Visual Experience. Philosophical Review 115: 355-88. - 2010. Do Visual Experiences Have Contents? In B. Nanay (ed.) Perceiving the World. Oxford: Oxford University Press.

Travis, C. 2004. The Silence of the Senses. Mind 113: 57-94.

Tye, M. 1992. Visual Qualia and Visual Content. In T. Crane (ed.) The Contents of Experience:

Essays on Perception. Cambridge: Cambridge University Press, p.158-76.

- 1995. Ten Problems of Consciousness: A Representational Theory of the Phenomenal Mind. Cambridge, MA: The MIT Press.

- 2000. Consciousness, Color and Content. Cambridge, MA: The MIT Press.

- 2007. Intentionalism and the Argument of No Common Content. Noûs 41: 589-613.

\author{
Marco Aurélio Sousa Alves \\ The University of Texas at Austin \\ Philosophy Department \\ 1 University Station C3500 \\ Austin, TX, USA, 78712 \\ marcoaurelioalves@utexas.edu
}

Resumo. A tese de que experiências perceptivas possuem conteúdo representacional, ou a teoria do conteúdo, tem sido alvo dos defensores da chamada teoria do objeto. Parte da disputa, conforme argumento nesse artigo, apóia-se na incompreensão da noção de conteúdo. Mas esse desacordo deve-se também, em parte, a questões substanciais. Uma vez que o núcleo substancial da disputa é trazido à tona, pretendo aqui: (1) rejeitar os argumentos levantados contra a teoria do conteúdo por Campbell (2002), Travis (2004) e Brewer (2006); (2) criticar as tentativas de Brewer $(2006,2007,2008,2011)$ de defender a teoria do objeto; (3) refinar os argumentos de Pautz $(2007,2008,2009,2010,2011)$ contra a teoria do objeto, que apelam principalmente para o fato dela não conseguir explicar o papel fundacional das experiências alucinatórias; (4) e finalmente julgar a questão a favor da teoria do conteúdo e contra a superestimação da intuição ingênua.

Palavras-chave: Teoria do conteúdo; teoria do objeto; conteúdo representacional; caráter fenomênico; intuição ingênua.

\title{
Notes
}

${ }^{1}$ I borrow this terminology from Brewer (2004), but I use these terms in a proprietary way.

Principia 16(3): 417-449 (2012). 
${ }^{2}$ I elaborate here on the arguments advanced by Pautz (2007, 2008, 2009, 2010, 2011).

${ }^{3}$ I confine myself here to perceptual experiences. Other phenomenally conscious states such as bodily sensations (e.g. feeling pain, feeling an itch, feeling hungry, feeling dizzy), emotions (e.g. feeling fear, love, jealousy) or moods (e.g. feeling happy, depressed, calm) fall beyond the scope of this paper.

${ }^{4}$ Though this paper aims at a general point concerning any kind of perceptual experience (through any of the senses), I focus almost exclusively on visual examples. I follow the common practice of doing that, and I share the belief that no danger comes from this onesided diet of examples.

${ }^{5}$ The sharing of the same phenomenal character by veridical and non-veridical experiences will be covered in more detail in section III.

${ }^{6}$ My characterization of the content view assumes that the intentional relation established between subject and content is that of representing. I use the terms intentional content and representational content interchangeably. I am aware that there are non-representational intentional accounts of perceptual content, but I ignore this possibility here, as these views are marginal in the current debates in philosophy of perception. If my terminology bothers you a lot, fell free to replace every use of 'representational' and its cognates for 'intentional'. I don't think it will affect my purposes here in any relevant sense.

${ }^{7}$ What contents are admissible for perceptual experiences is a highly polemical issue. Though I include properties, objects and relations in my rough characterization here, I am not committed to any particular view on that matter. I am also neutral on any specific account of representational content (as conceptual or nonconceptual, Russellian or Fregean propositions, sets of possible worlds, property-complexes, or whatever). Given my purposes here, I can perfectly be neutral on all that. Fell free to fill in the details with your favored accounts. ${ }^{8}$ As a matter of fact, it is controversial whether particular objects are represented in perceptual experiences. Even if they are represented in veridical perceptions, it is less likely that they can also be represented in hallucinatory experiences. I leave these issues aside, as I am not after a detailed theory of representational content here.

${ }^{9}$ I tried to characterize the content view in very rough terms, so that a wide range of philosophers could be counted as defending something along these lines. I have in mind people like Drestke, Tye, Lycan, Shoemaker, Byrne, Siegel, Pautz, among many others.

${ }^{10}$ The term acquaintance is the most commonly used to name this relation. I prefer, however, to use the more neutral term direct relation.

${ }^{11}$ Pautz (2009) also wants to determine what the contents of perceptual experiences should be like. He is after a notion of content that does not trivialize both the debate concerning whether or not experiences have contents, and the question concerning what the contents are (whether they are purely general or singular, if they include natural kinds or not, and so on). Since I am not concerned here with the second part of his project, I focus exclusively on the attempt of making the first debate nontrivial. Since my scope is more restricted, the whole structure of his arguments will be properly modified so as to fit my more modest objectives.

${ }^{12}$ Moreover, the appears-looks conception faces the challenge of isolating (by the analysis of linguistic marks alone) the specifically phenomenal use of looks-appears reports. Only this use of reports should be any relevant to determining the contents of experiences, and there is no clear way of telling the various uses apart. If I say, for instance, that a tomato looks

Principia 16(3): 417-449 (2012). 
expensive, this looks-report seems irrelevant to determining phenomenal contents. It seems that the specifically phenomenal element of appears-looks reports can hardly be isolated in a non-arbitrary way.

${ }^{13}$ See Siegel (2010, p.34).

${ }^{14}$ For present purposes, I can be neutral on the strong or weak versions of this thesis. The weak version only claims that the phenomenal character is partly equated with the content. This can be contrasted with the strong claim that "phenomenal character (or what it is like) is one and the same as a certain sort of intentional content" (Tye 1995, p.137, emphasis mine). The weak claim leaves it open if qualia (or any other nonrepresentational element) also affect the phenomenology of perceptual experience. The weak version is enough to make the conception of content nontrivial, and that is all I need here.

${ }^{15}$ McDowell (1986) advances a similar argument, but I focus here exclusively in Campbell's version.

${ }^{16}$ What Campbell (2002) calls the "Representational View" corresponds to what I call the content view. He contrasts this view with the "Relational View", which is a version of what I call the object view. To avoid misunderstanding, I will, in what follows, stick to my favored terminology.

${ }^{17}$ Pautz (2010, p.284) draws an important distinction between the "phenomenal question", answered by the content view, and the "success question", concerning the "nature of successful perception". The account of (veridically) perceiving something as having a relation to a content plus a certain causal relation between content and object perceived, though the standard view, is not obligatory for the defender of the content view. As far as the content view goes, veridically perceiving can be a radically different state from nonveridical experiences.

${ }^{18}$ Byrne (2009) remarks that Travis (2004) ignores the most promising use of the term "looks", that was labeled by Jackson (1977) the "phenomenological use". But adding more subtlety to the linguistic analysis will hardly change the verdict that content is not looksindexed. This will certainly not affect the point that I want to make here.

${ }^{19}$ Byrne (2009, p.444) stresses that the content view "is not a claim about how we talk". Phenomenal character is not a linguistic phenomenon. Whatever support there may be for the content view, it is not to be found in subtleties concerning the use of certain words.

${ }^{20}$ Byrne (2009, p.440) notices that "on one popular account, representation (and perceptual presentation in particular), precisely is a matter of what things indicate (under certain conditions)". Tree rings and cat patches are used, ironically, to motivate the notion of representational content. In what follows, I prefer to press a different point, but this comment by Byrne is suggestive of the fact that the view defended by Travis does not touch upon the core of the content view. As far as the content view goes, different accounts of what representing amounts to can fit the bill.

${ }^{21}$ I prefer this argument against Travis (2004) than the one proposed by Byrne (2009). Byrne (2009) rejects Travis' (2004) position on the grounds that it cannot adequately account for illusions. Take the Müller-Lyer diagram, for instance. Byrne (2009, p.445) claims that Travis is committed to saying that the lines look "as if they are unequal". The illusory experience, nonetheless, "does not imply that I have some tendency to believe that" (Byrne 2009 , p.445). The power of indicating something is, according to Travis (2004), an objective fact concerning things in the world. Things just have an "objective look". Travis (2004, p.68) says, for instance, that the Müller-Lyer lines "do not just seem to have that look; that

Principia 16(3): 417-449 (2012). 
is actually the way they look. (Witness the 'robustness' of the illusion)". Byrne (2009, p.446) presses the point that, according to Travis' account, the lines, properly speaking, do not look unequal: their "objective look" indicates that they are unequal (or they just look as if they are unequal). But "looking as if" is an epistemological attitude that involves judgment: the Müller-Lyer lines can look unequal even if they don't look as if they are unequal. This is the case if the subject does not believe that they are unequal; if, for instance, the subject is aware of the illusory nature of the experience. Byrne (2009, p.447) concludes that Austin's idea (that perception "simply places our surroundings in view") immediately puts the explanation of illusion as a challenge. Byrne (2009) is certainly right that the defender of any version of the object view has the theoretical burden of explaining the phenomenology of illusions. But, as noted by Pautz (2009, p.496), there are disjunctive accounts of illusion on the market that may fit the bill. Giving no account of something does not mean that no account can be given. Travis' (2004) proto-version of the object view is certainly very schematic. It is, in fact, just a collection of insights. The underdeveloped nature of his ideas, however, can hardly make Byrne's criticism interesting. Byrne's point is too easily vindicated because his opponent is not in the business of developing a full-fledged account of illusion. Instead of the quick-and-easy criticism advanced by Byrne (2009), I prefer to investigate how, and to what extent, Travis' argument actually concerns the content view.

${ }^{22}$ Pautz (2010, p.287) claims that the content view is not committed to provide a "reductive psychosemantics", or some kind of procedure for determining content. This is a massively empirical enquiry, and the defender of the content view can be neutral about the details of such vastly empirical investigation.

${ }^{23}$ Pautz (2009, p.498) makes the same point and claims that the content view is perfectly compatible with error being a matter of false beliefs instead of false contents.

${ }^{24}$ Whatever terminology one chooses, the "metaphors" mentioned by Austin (1962, p.11) can be properly paraphrased. Sometimes it is hard to separate, in Travis (2004), the substantive claims about the nature of perception from the mere verbal issues concerning the use of some locutions.

${ }^{25}$ Brewer (2006, p.174) claims that the general way in which things are represented in the content "trades direct openness to the elements of physical reality themselves, for some intellectual act of classification or categorization". A lot here seems to depend on a substantial metaphysical account of properties. I prefer not to deal with this massive (and very complicated) topic here. Hopefully, I am right in believing that the relevant point of this paper can be satisfactorily motivated without any appeal to such matters.

26 The naïve intuition concerns what Brewer calls the "fundamental difference" between perception and thought. There are, certainly, other remarkable differences between them. Many emphasize, for instance, that perceptual experiences themselves do not necessarily involve concepts, whereas thoughts do. If, for example, I look at a duck and it looks duck-like to me, it does not require my possession of the concept $<$ duck $>$, whereas thinking that it looks duck-like does. This distinction will be further explored in what follows. For the moment, I want to highlight that Brewer is simply bringing our attention to a putative difference between perception and thought: a difference that he takes to be deeply important.

27 The object view, on the other hand, accounts for the Müller-Lyer illusion in roughly the following terms: given a certain perceptual context (viewpoint, circumstance of perception), a Müller-Lyer diagram has relevant similarities with paradigms of lines of unequal length.

Principia 16(3): 417-449 (2012). 
Consequently, the perceiver is misled by the diagram. The object view, according to Brewer, has no difficulty to explain this case.

${ }^{28}$ Contrary to Pautz (2010, p.266), I adopt a weaker version of the grounding intuition. Pautz needs a stronger version (i.e., necessarily, if the individual who has the capacity to have beliefs has a hallucinatory experience for a sufficient period of time, then he thereby has the additional capacity to have novel general beliefs) because he is also arguing against nonrelational (qualia) accounts of hallucination. My argument has a narrower scope. I am not committed to hallucinatory states being (necessarily) externally-directed. The weaker claim that hallucinations can (possibly) endow individuals with the capacity to have beliefs that they could not have before is enough for my present purposes.

${ }^{29}$ Pautz $(2009,2011)$ credits the grounding intuition to Johnston (2004). But, according to Pautz (2011, p.20), Johnston's version has an epistemological character (i.e., it concerns the justification of beliefs about the world). This strikes me as wrong. Johnston (2004) is also concerned with the res that makes de re beliefs of phenomenal properties possible. This deeper motivation is not merely epistemological, but concerns the very possibility of having certain beliefs.

30 Johnston (2004, p.141) takes this experiment from Hurvich (1982, p.187).

${ }^{31}$ This experiment also suggests that the content of hallucinatory experiences cannot be fully explained in terms of the contents of veridical experiences previously undergone by the subject. The supersaturated red can never be experienced in actuality, though it can be hallucinated. This case suggests that the content of a hallucination is not simply brought to that state from an earlier veridical state and memory. The same point can be made by the thought experiment in which Mary hallucinates red patches in her black-and-white room and is thereby capable of having colorful thoughts.

32 Martin (2006), for instance, defines disjunctivism in terms of "fundamental kinds" of experience; Byrne and Logue (2008) in terms of different "mental states". See Pautz (2010) for a criticism of these views and for a detailed analysis of the various kinds of disjunctivism. ${ }^{33}$ Kalderon and Travis (2009) trace the historical origins of this connection. They believe that, while Austin was not explicit about that, he was committed to a disjunctivist view. Only after Hinton (1973) this connection became fully explicit.

${ }^{34}$ I am neutral here on whether or not illusions should also be dealt with disjunctively. I grant, for the sake of the argument, that illusions can be accounted for together with veridical experiences, in a Brewer-like kind of approach.

35 The positive disjunctivist account can characterize hallucination in terms of relations with non-physical entities (e.g., sense data, or Meinongian entities), or in nonrelational terms (e.g., qualia).

${ }^{36}$ I leave the rejection of positive disjunctivist accounts of hallucination to another opportunity. Some versions of this view involve heavily loaded metaphysical questions that I prefer not be entangled with at this moment.

${ }^{37}$ Brewer (2011) follows mainly Martin (2004) on that matter.

${ }^{38}$ A defender of the object view may argue that this premise is question-begging. I agree with Pautz (2010, p.278) that this premise is based upon a deeply entrenched intuition, and simply rejecting it cannot be done without "a serious cost". Moreover, the defenders of the object view are happy to start their whole theoretical enterprise motivated by an intuition (namely, the naïve intuition). They are not entitled to deny the right of intuitions to motivate

Principia 16(3): 417-449 (2012). 
theorizing. The object view takes the naïve intuition as a datum that must be accommodated: by the same token, the grounding intuition has all the rights to be a datum.

39 Pautz (2010, p.278) credits this argument to David Chalmers.

${ }^{40}$ An independent support for the idea that the world is not only made of objects, but also of general properties, comes from the fact that it is not entirely clear that all perceptual experiences are directed towards particular objects. Byrne (2009, p.448) notices that it is not clear that in smelling and tasting there is a particular object that instantiates the relevant properties. The content view can easily account for such cases by using some sort of quantified proposition, or property-complexes.

${ }^{41}$ The grounding intuition concerning objects is, curiously, the main argument used by Campbell (2002) to reject the content view.

42 Objecting that the verb "to track" is a success-verb like "to see" is obviously besides the point. I am not making a linguistic remark about the use of the term "to track" in English.

${ }^{43}$ It may be objected that we have a good grasp of the idea of tracking physical objects, but it is entirely mysterious what the tracking conditions for hallucinatory objects would be like. However, I believe that we have a fairly good grasp of the notion of tracking in such cases. Take, for example, empirical evidence on animals' hallucinations. Nielsen et al. (1983) studied the behavioral effects of the administration of amphetamine to monkeys and concluded that they had hallucinatory experiences based, among other things, on observed behaviors such as "attack or sudden threat reactions directed at invisible objects", or "visual tracking of invisible objects, sometimes involving coordinated patterns of 'eating behavior"'. The observed behaviors can be considered hallucinatory because no eliciting stimuli could be determined for their occurrence. If the administration of a hallucinogenic drug leads a monkey to visually track invisible objects, we have quite good reasons to believe that the invisible objects being tracked are hallucinatory ones. (Thanks to the anonymous reviewer for bringing attention to this problem).

44 The deeper reason why Brewer cannot accept the grounding intuition is, in my opinion, his commitment to a certain metaphysical theory. He (2011, p.81) explicitly adopts a nominalist view of general properties, and therefore he denies their genuine existence in the mindindependent world. He does not argue for this view, though.

${ }^{45}$ Siegel (2010) and Tye (2007) claim that the naïve intuition can be accommodated by the content view. However, they seem not to have in mind a strictly phenomenological understanding of the naïve intuition. If the naïve intuition is understood as the mere claim that, in veridical experience, the subject is directly in contact with the perceived object, then the intuition becomes much weaker and it can be accommodated in various ways by the content view. However, as it is understood in this paper, the naïve intuition amounts to the claim that the phenomenal character of perceptual experience is nothing but the direct presentation of objects in experience.

46 This paper was funded by Capes Foundation, Ministry of Education of Brazil.

Principia 16(3): 417-449 (2012). 